\title{
SEBUAH REVIEW PERANCANGAN WEBSITE SEBAGAI MEDIA PEMASARAN DAN PENJUALAN INDUSTRY XYZ FLORIST
}

\author{
Putu Gede Surya Cipta Nugraha \\ Program Studi Teknik Industri, Fakultas Teknik, Universitas Mahendradatta \\ Jl. Ken Arok No.12, Peguyangan, Denpasar, Bali 80115 \\ E-mail : surya.ciptanugraha@gmail.com
}

\begin{abstract}
Abstrak- Dalam usaha industry xyz florist sangat dibutuhkan sarana dan prasarana dalam melakukan kegiatan pemasaran dan penjualan, hal ini bertujuan agar industry xyz florist dapat diketahui oleh masyarakat luas serta meningkatkan omzet. Saat ini pemasaran yang dilakukan oleh industry xyz florist masih kurang dikelola dengan baik. Pemasaran dan penjualan masih dilakukan dengan secara konvensional dengan membuka stand-stand kecil dipinggir jalan saat valentine, menggunakan brosur-brosur, serta penawaran bekerja sama dengan usaha-usaha lainnya. Untuk mengatasi permasalahan tersebut maka dilakukan perancangan website untuk mendukung kegiatan pemasaran dan penjualan industry xyz florist. Perancangan website pemasaran dan penjualan menggunakan tools CMS (Content Management System). Dengan adanya website ini, kegiatan pemasaran dan penjualan akan lebih maksimal sehingga omset dari usaha industry $x y z$ florist dapat meningkat.
\end{abstract}

Kata Kunci : Website, CMS, Home Industry

\begin{abstract}
In the xyz florist industry business, facilities and infrastructure are urgently needed in conducting marketing and sales activities, so that the xyz florist industry can be known to the wider community and increase turnover. Currently the marketing carried out by the xyz florist industry is still poorly managed. Marketing and sales are still done conventionally by opening small booths on the roadside during valentine, using brochures, and offering to work with other businesses. To overcome these problems, website design is done to support the marketing and sales activities of the $x y z$ florist industry. Website marketing and sales design using CMS (Content Management System) tools. With this website, marketing and sales activities will be maximized so that the turnover of the xyz florist industry can increase.
\end{abstract}

Keywords: Website, CMS, Home Industry

\section{PENDAHULUAN}

Persaingan bisnis pada zaman ini sangatlah menuntut pelaku bisnis untuk selalu mengikuti perkembangan pasar. Menurut Menurut Mankiw (2007) pasar adalah sekumpulan pembeli dan penjual dari sebuah barang atau jasa tertentu. Para pembeli sebagai sebuah kelompok yang menentukan permintaan terhadap produk dan para penjual sebagai kelompok yang menentukan penawaran terhadap produk (Zayinul Fata, 2010). Suatu usaha dalam menjalankan aktivitasnya harus secara maksimal melakukan kegiatan pemasaran serta penjualan, agar usaha dapat diketauhi oleh masyarakat luas yang berdampak pada target keuntungan dapat terwujud dengan baik. Hal ini menandakan bahwa pelaku bisnis harus kreatif dan inovatif.

Industry xyz florist adalah usaha kecil yang bergerak dalam penjualan rangkaian bunga hias. Kegiatan pemasaran yang dilakukan oleh usaha industry $x y z$ florist saat ini masih belum berjalan dengan baik, yang berimbas pada omset yang tidak mencapai target. Saat ini promosi masih dilakukan secara konvensional, dengan membuka stand-stand kecil dipinggir jalan 
saat valentine, menggunakan brosurbrosur, serta penawaran bekerja sama dengan usaha-usaha lainnya selain itu kemampuan sumber daya manusia dalam memanfaatkan teknologi juga masih kurang.

Menurut Jauhari (2010), Bidang bisnis dan perdagangan yang berkembang saat ini sangat terpengaruh dengan perkembangan teknologi informasi khususnya dalam penggunaan internet. Dengan adanya internet dan Information and Communication Technology (ICT), proses pemasaran dan penjualan dapat dilakukan kapan saja tanpa terikat ruang dan waktu (Quaddusand Xu, 2008; Jinling et al., 2009).

Membangun sebuah website hanyalah sebagai langkah awal untuk menghadapi persaingan bisnis, yang secara tidak langsung menuntut pelaku bisnis untuk selalu mengikuti perkembangan zaman. Hal ini dapat dibandingkan jika harus membuka cabang baru untuk memperluas pemasaran, tentu biaya yang dibutuhkan lebih besar. Dengan kemampuan internet yang dapat mengirimkan gambar, suara, data, video banyak pelaku bisnis yang memanfaatkan teknologi tersebut untuk melakukan pemasaran dan penjualan. Disamping biayanya relatif murah, dengan memanfaatkan internet penyebaran informasi akan lebih cepat dan jangkauannya lebih luas (Rizal dkk.,2013; Supardi, 2009).

Dari latar belakang diatas penulis tertarik mengangkat topik perancangan website sebagai media pemasaran dan penjualan industry $x y z$ florist.

\section{KAJIAN PUSTAKA}

a. Internet

Purbo (dalam Prihatna, 2005) menjelaskan bahwa Internet pada dasarnya merupakan sebuah media yang digunakan untuk mengefesiensikan sebuah proses komunikasi yang disambungkan dengan berbagai aplikasi, seperti Web, VolP, E-mail.

b. Website

Abdullah (2015) Website dapat diartikan sekumpulan halaman yang terdiri dari beberapa laman yang berisi informasi dalam bentuk data digital baik berupa text, gambar, video, audio, dan animasi lainnya yang disediakan melalui jalur koneksi internet.

c. Entity Relationship Diagram (ERD)

Brady dan Loonam (2010), Entity Relationship diagram (ERD) merupakan teknik yang digunakan untuk memodelkan kebutuhan data dari suatu organisasi, biasanya oleh System Analys dalam tahap analisis persyaratan proyek pengembangan system.

d. Contex Diagram (CD)

Ladjamuddin (2006) Contex Diagram adalah diagram yang terdiri dari suatu proses dan menggambarkan ruang lingkup suatu sistem. Diagram konteks merupakan level tertinggi dari DFD yang menggambarkan seluruh input ke sistem atau output dari sistem. la akan memberi gambaran tentang keseluruan sistem.

e. Data Flow Diagram(DFD)

DFD sering digunakan untuk menggambarkan suatu sistem yang telah ada atau sistem baru yang akan dikembangkan secara logika tanpa mempertimbangkan lingkungan fisik dimana data tersebut mengalir.

f. Use Case

Use case diagram menurut Satzinger (2010) merupakan rangkaian tindakan yang dilakukan oleh sistem, aktor mewakili user atau sistem lain yang berinteraksi dengan sistem yang dimodelkan.

\section{METODE PENELITIAN}

Dalam penelitian ini menggunakan model proses waterfall. Metode waterfall memiliki beberapa tahapan yang berurut yaitu: requirement (analisis kebutuhan), design system (desain sistem), Implementation, Verification \& testing (pengujian) dan Maintenance (pemeliharaan) 


\section{HASIL DAN PEMBAHASAN}

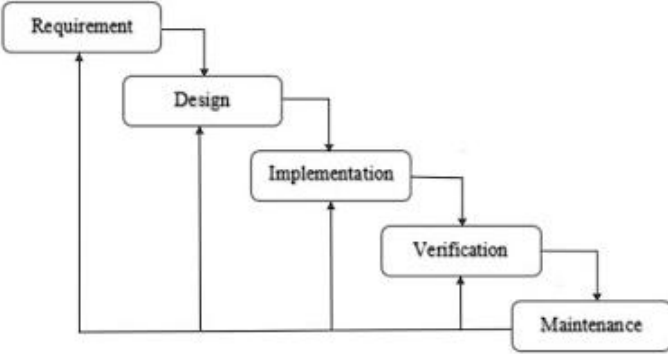

Gambar 1 Model Proses Waterfall Sumber: www.google.com

\section{a. Requirement}

Pada tahap ini dilakukan proses analisis kebutuhan, untuk memahami apa saja yang diperlukan oleh pelaku usaha industry $x y z$ florist (administrator) dan pelanggan.

\section{Analisis Kebutuhan Non Fungsiional}

1. Analisis kebutuhan perangkat keras : satu unit komputer/laptop dengan spesifikasi processor core i5, HDD dengan kapasitas $1 \mathrm{~TB}, \quad R A M$ dengan besaran $4 \mathrm{~GB}$, Printer (print, copy dan scan), dan infrastruktur internet.

2. Analisis kebutuhan perangkat lunak : OS Win 1064 bit, Xampp, MySQL, Browser (Mozilla firefox atau google chrome) dan CMS.

3. Analisis kebutuhan sumber daya manusia antara lain: administrator dan pelanggan. Administrator merupakan seorang yang dapat mengolah database dan update informasi sedangkan pelanggan merupakan semua orang yang dapat mengakses website industry xyz florist.

\section{Analisis Kebutuhan Fungsional}

Dari proses requirement yang sudah ditentukan, berikut kebutuhan fungsionalitas system industry $x z y$ florist yang dibutuhkan :

1. System website $x y z$ florist memiliki 2 halaman. Yaitu halaman khusus administrator dan halalam khusus pelanggan.
2. Halaman administrator merupakan halaman yang dapat diakses oleh administrator, dalam hal ini adalah pemilik usaha industry $x y z$ florist. Administrator dapat melakukan login, memposting design-design bunga terbaru, update informasi, dan mengontrol keseluruhan data.

3. Halaman pelanggan merupakan halaman yang dapat diakses oleh pelanggan. Pelanggan dapat melakukan registrasi, melihat design-design bunga yang ingin dipesan, dan melakukan pemesanan.

\section{b. Design}

Pada tahap ini, akan dilakukan proses design website industry xyz florist, yang dibuat berdasarkan kebutuhan yang direkomendasikan pada tahap requirement.

Dalam tahap design terdapat dua design yaitu Use Case dan ERD. Use Case akan menjelaskan tindakan yang dapat dilakukan oleh pelanggan, administrator dan system, sedangkan ERD menjelaskan percancangan database dari website pemasaran dan penjualan $x y z$ florist.

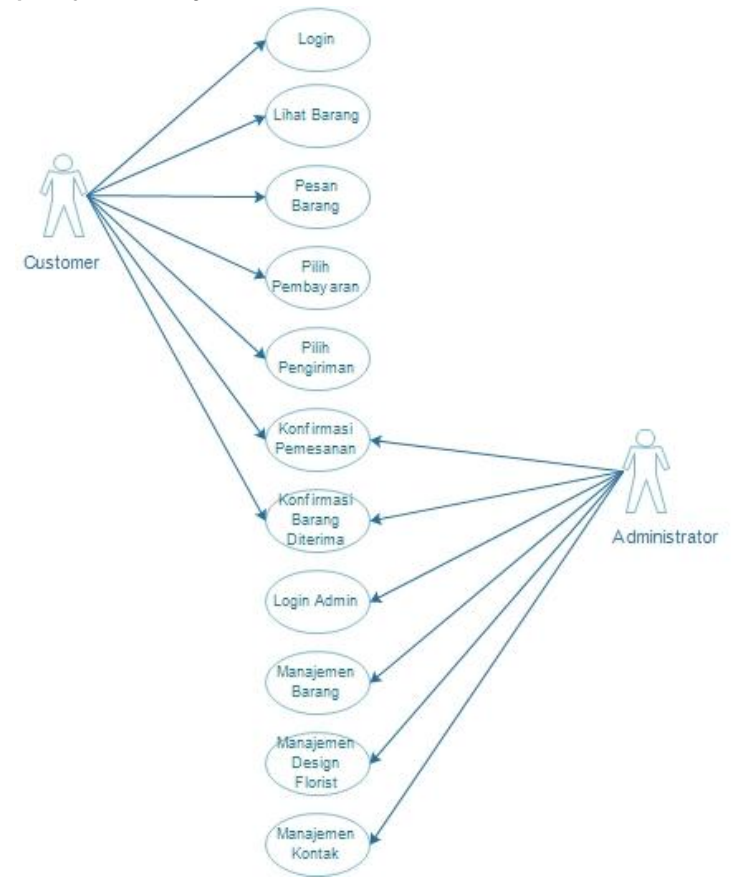

Gambar 2 Use Case Website Florist 
Pada gambar 2 dapat dilihat use case design dari website $x y z$ florist. Pada gambar tersebut ada 2 aktor yang memiliki peranan sangat penting yaitu pelanggan dan administrator. Pada aktor administrator, administrator dapat melakukan login, konfirmasi pemesanan, konfirmasi barang diterima, Manajemen barang, manajemen design barang dan manajemen kontak, sedangkan pada pelanggan, pelanggan dapat melakukan login, lihat barang, pesan barang, pilih pembayaran, pilih pengiriman, konfirmasi pesanan dan konfirmasi barang diterima.

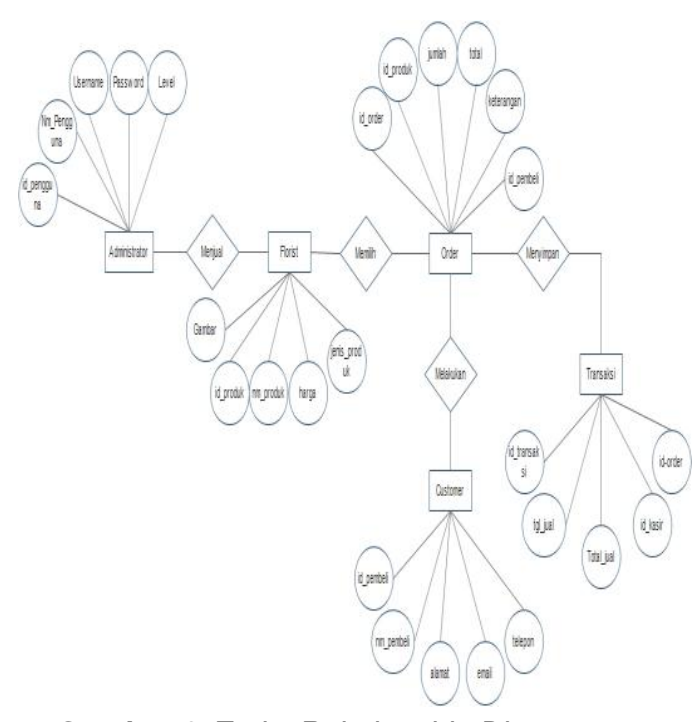

Gambar 3 Entity Relationship Diagram

Pada gambar 3 dapat dilihat Entity Relationship Diagram proses pelanggan melakukan order dan memilih barang pada website $x y z$ florist.

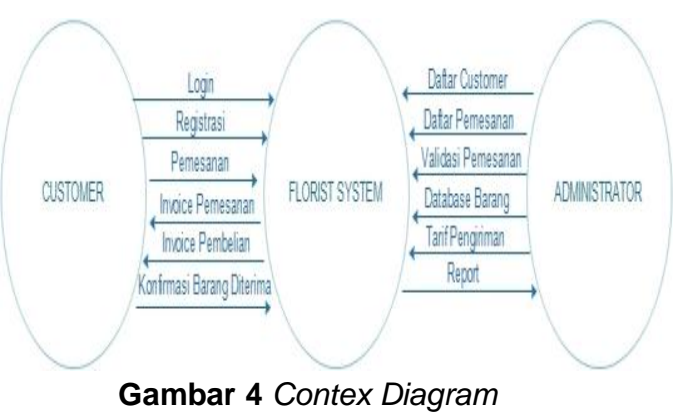

Pada gambar 4 dapat dilihat Contex Diagram dari system. Contex diagram menggambarkan seluruh input ke sistem atau output dari system.

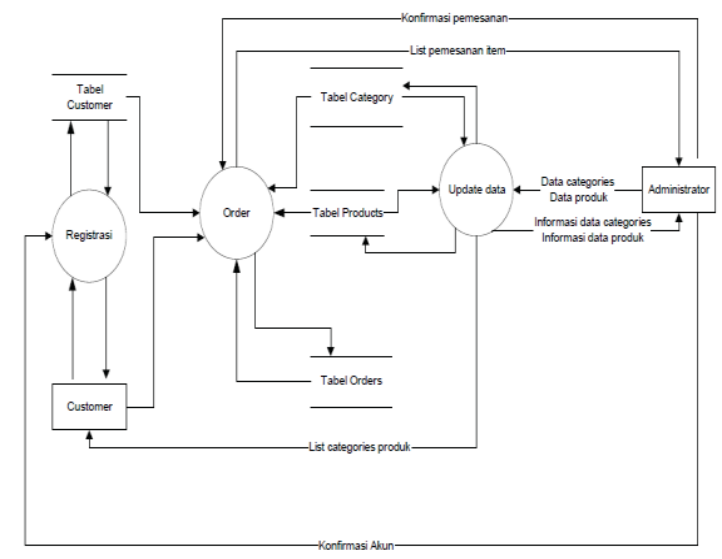

Gambar 5 DFD Level 0

Pada gambar 5 dapat dilihat bahwa proses bisnis yang ada pada website $x y z$ florist ada tiga yaitu registrasi, pemesanan dan update informasi oleh administrator. Pada proses login pelanggan melakukan registrasi untuk mendapatkan account. Pada proses pemesanan pelanggan memilih produk bunga yang akan dibeli dan pada proses update administrator bisa melakukan update informasi.

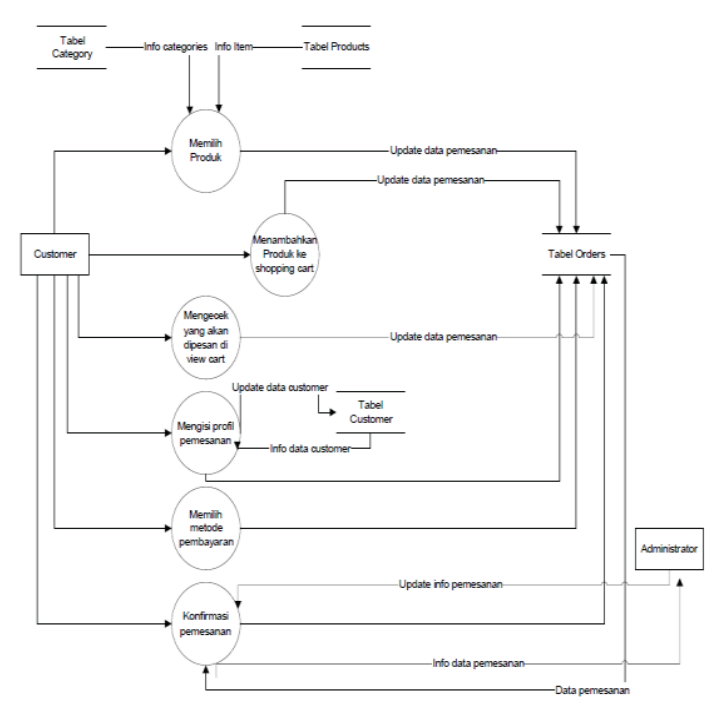

Gambar 6 DFD Level 1

Pada gambar 6 dapat dilihat bahwa pelanggan melakukan proses 
pembelian produk bunga. Sebelum melakukan pembelian, pelanggan dapat melihat lihat design bunga yang nantinya akan dipilih. Ketika pelanggan sudah menentukan pilihan, produk tersebut dapat dimasukan kedalam tas belanja. Pelanggan juga melakukan proses pengecekan untuk mengetahui apakah produk yang masuk dalam tas belanja sudah sesuai. Jika belum sesuai pelanggan dapat memilih produk kembali, Jika produk yang dipesan sudah sesuai maka pelanggan bisa melakukan proses pembayaran

\section{c. Implementation}

Pada tahap ini akan dilakukan proses implementasi, masing-masing unit diintegrasikan dan dikembangkan agar fungsi sudah sesuai dengan kebutuhan. Berikut adalah tampilan dari hasil design dan perancangan website.

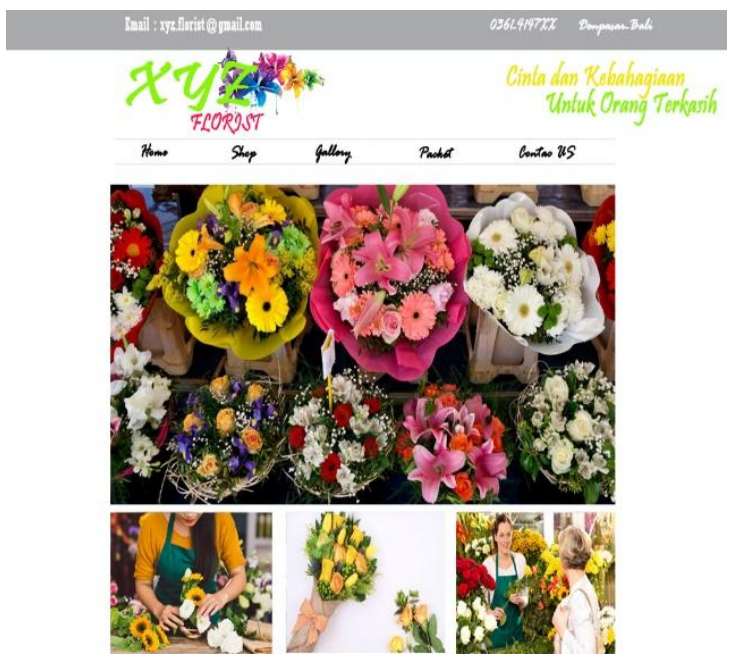

Gambar 7 Tampilan Website Xyz Florist

Pada gambar 7 dapat dilihat tampilan website $x y z$ florist. Pada halaman ini administrator dapat melakukan update informasi seperti design-design bunga, harga dan lain sebagainya. Dari sisi pelanggan dapat melakukan pengecekan serta pembelian bunga.

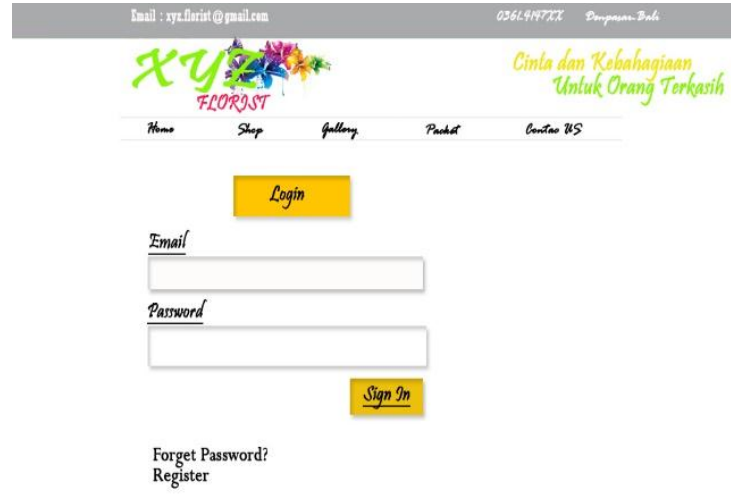

Gambar 8 Tampilan Login

Pada gambar 8 dapat dilihat tampilan login dari website $x y z$ florist. Pada form ini pelanggan atau administrator harus menginputkan alamat email dan password yang didaftarkan ketika melakukan registrasi. Pelanggan yang lupa dengan password dapat menggunakan fitur forget password. Jika pelanggan ingin melakukan pendaftaran dapat menggunakan menu registrasi.

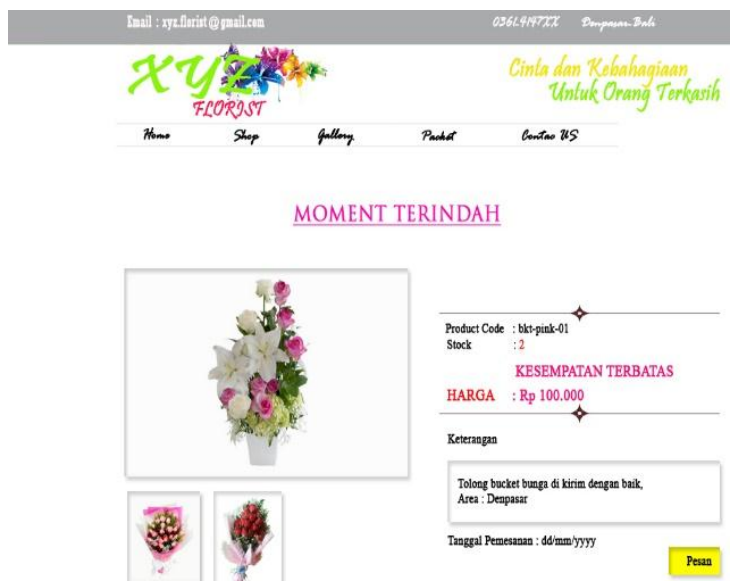

Gambar 9 Tampilan Pemesanan Bunga

Pada gambar 9 dapat dilihat tampilan website $x y z$ florist. Pada halaman ini pelanggan dapat melakukan proses pemesanan bunga, tertera juga stock yang tersedia, tanggal pemesanan beserta harga bunga. Pada bagian bawah bunga dipilih juga tertera gambar bunga lainnya. Selama proses pesan belum dilakukan, pelanggan masih bisa memilih atau melihat model bunga yang lain. 


\section{d. Verification and Testing}

Tabel 1 Verification and Testing

\begin{tabular}{|c|c|c|c|c|}
\hline No & Pengujian & $\begin{array}{l}\text { Hasil yang } \\
\text { diharapkan }\end{array}$ & $\begin{array}{l}\text { Hasil } \\
\text { Pengujian }\end{array}$ & Hasil \\
\hline 1 & $\begin{array}{l}\text { Mengosongkan } \\
\text { semua isian } \\
\text { login, lalu klik } \\
\text { sign in }\end{array}$ & $\begin{array}{l}\text { System akan } \\
\text { menolak } \\
\text { akses login }\end{array}$ & $\begin{array}{l}\text { Sesuai } \\
\text { harapan }\end{array}$ & valid \\
\hline 2 & $\begin{array}{l}\text { Login sebagai } \\
\text { administrator }\end{array}$ & $\begin{array}{l}\text { System akan } \\
\text { mengarahka } \\
\mathrm{n} \quad \mathrm{ke} \\
\text { halaman } \\
\text { admnistrator }\end{array}$ & $\begin{array}{l}\text { Sesuai } \\
\text { harapan }\end{array}$ & valid \\
\hline 3 & $\begin{array}{l}\text { Login sebagai } \\
\text { pelanggan }\end{array}$ & $\begin{array}{l}\text { System akan } \\
\text { mengarahka } \\
\mathrm{n} \quad \mathrm{ke} \\
\text { halaman } \\
\text { pelanggan }\end{array}$ & $\begin{array}{l}\text { Sesuai } \\
\text { harapan }\end{array}$ & valid \\
\hline 4 & $\begin{array}{l}\text { Admin } \\
\text { melakukan } \\
\text { update } \\
\text { informasi }\end{array}$ & $\begin{array}{l}\text { Informasi } \\
\text { pada website } \\
\text { diperbeharui }\end{array}$ & $\begin{array}{l}\text { Sesuai } \\
\text { harapan }\end{array}$ & valid \\
\hline 5 & Fitur home & $\begin{array}{l}\text { Menampilkan } \\
\text { tampilan } \\
\text { depan } \\
\text { website } \\
\text { (ucapan } \\
\text { selamat } \\
\text { datang) }\end{array}$ & $\begin{array}{l}\text { Sesuai } \\
\text { harapan }\end{array}$ & valid \\
\hline 6 & Fitur Shop & $\begin{array}{l}\text { Menampilan } \\
\text { jenis-jenis } \\
\text { rangkaian } \\
\text { bunga } \\
\text { beserta } \\
\text { proses } \\
\text { pembelian }\end{array}$ & $\begin{array}{l}\text { Sesuai } \\
\text { harapan }\end{array}$ & valid \\
\hline 7 & Fitur gallery & $\begin{array}{l}\text { Menampilkan } \\
\text { gambar } \\
\text { gambar } \\
\text { pelanggan } \\
\text { atau rekan } \\
\text { bisnis yang } \\
\text { bekerja }\end{array}$ & $\begin{array}{l}\text { Sesuai } \\
\text { harapan }\end{array}$ & valid \\
\hline 8 & Fitur packet & $\begin{array}{l}\text { Menampilkan } \\
\text { promo- } \\
\text { promo }\end{array}$ & $\begin{array}{l}\text { Sesuai } \\
\text { harapan }\end{array}$ & valid \\
\hline 9 & Fitur contact us & $\begin{array}{l}\text { Menampilan } \\
\text { informasi } \\
\text { identitas } \\
\text { usaha }\end{array}$ & $\begin{array}{l}\text { Sesuai } \\
\text { harapan }\end{array}$ & valid \\
\hline 10 & $\begin{array}{l}\text { Testing } \\
\text { pembelian } \\
\text { barang oleh } \\
\text { pelanggan }\end{array}$ & $\begin{array}{l}\text { Pelanggan } \\
\text { dapat } \\
\text { melakukan } \\
\text { proses } \\
\text { pembelian }\end{array}$ & $\begin{array}{l}\text { Sesuai } \\
\text { harapan }\end{array}$ & valid \\
\hline
\end{tabular}

Dari hasil pengujian tidak ada error/bug pada website $x y z$ florist, semua fungsi telah berjalan dengan baik, sebagaimana mestinya.

\section{e. Maintenance}

Proses ini dilakukan berkala dan dikembali lagi kepada tahap requirement antara administrator dan pelanggan

\section{KESIMPULAN DAN SARAN}

\section{a. Kesimpulan}

Perancangan website $x y z$ florist sebagai sarana dan prasarana pemasaran dan penjualan industry $x y z$ florist sudah berhasil dibangun. Website ini memberikan kemudahan kepada pemilik usaha dan pelanggan untuk memperoleh informasi dari $x y z$ florist. Dengan adanya website industry $x y z$ florist, maka kegiatan pemasaran dapat dilakukan secara maksimal serta omset penjualan dapat meningkat.

\section{b. Saran}

Pembuatan website $x y z$ florist ini masih terbilang sederhana, terlihat dari segi tampilan, untuk tahap pengembangan selanjutnya di harapkan dibuat semenarik mungkin dengan tambahan informasi yang lebih lengkap lagi.

\section{DAFTAR PUSTAKA}

Abdullah, Rohi. 2015. Web Programing is Easy. Jakarta: Elek Media Komputindo.

Al-Bahra Bin Ladjamudin. 2006. Analisis dan Desain Sistem Informasi. Graha IImu. Yogyakarta.

Brady, M., \& Loonam, J. (2010). Exploring the use ofentity-relationship diagramming as a technique to support grounded theory inquiry.Bradford: Emerald Group.

Fata,Zayinul.2010.analisis Faktor-Faktor Yang Mempengaruhi Pendapatan Pedagang Batik (studi kasus pasar klewer Solo,Jawa Tengah). Tesis Jurusan Ekonomi Pembangunan Universitas Sebelas Maret Surakarta. Jauhari, J., 2010. Upaya Pengembangan Usaha Kecil dan Menengah (UKM) 
dengan Memanfaatkan E-Commerce, Jurnal Sistem Informasi, 2(1), 159-168.

Jinling, C., Tong, S., Chunan, L., and Tao, S., 2009. Modeling E-Commerce Website Quality with Quality Function Deployment, IEEE

Mankiw, N. Gregory. 2007. Makro Ekonomi, Edisi ke-6. Jakarta: Erlangga.

Onno, Purbo dan Aang. 2004. Mengenal e-commerce. PT.Elex media komputindo. Jakarta.

Prihatna Henky. 2005. Kiat praktis menjadi web master professional. PT.Elex media komputindo. Jakarta.

Quaddus, M. and Xu, J. 2008. Adoption of e-Commerce: A Decision Theoretic Framework and an Illustrative
Application, 10th International Conference on Computer and Information Technology.

Rizal, Bahauddin A., dan Ummi, N., 2013. Perancangan E-Commerce IKM Produk Industri Kreatif Kota Serang, Jurnal Teknik Industri, 1(4), 328 -333.

Satzinger, Jackson, Burd. 2010. "System Analisis and Design with the Unified Process". USA: Course Technology, Cengage Learning.

Supardi, J., 2009. Rancang Bangun Collaborative Sistem Pemasaran Hotel Secara On-line dengan Pendekatan Mediator Based, Jurnal Sistem Informasi, 